\title{
Sequential Bargaining, External Effects of Agreement, and Public Intervention
}

\author{
Margrethe Aanesen*
}

\begin{abstract}
In some bargaining situations, agreement has implications for agents beyond the parties involved, and if so, delays in reaching an agreement or failing to reach an agreement, when this would be profitable, may imply significant welfare losses. The question raised in this paper is whether the intervention of a government, who has a positive valuation of agreement and therefore offers a subsidy, will reduce such delays and inabilities to reach agreement? Based on a perfect Bayesian equilibrium in a sequential bargaining game with intervention, we show that in equilibrium intervention always reduces the ex ante equilibrium inefficiency and conditionally reduces expected delays in trade. However, for intervention in the form of a subsidy to take place, the aggregate of the seller's reservation price and the externalities must be (almost) as high as the buyer's upper valuation limit.
\end{abstract}

Keywords: sequential bargaining, external effects, public intervention, delays in trade, equilibrium inefficiency

JEL: D82, H24

* University of Tromso, Faculty of Biosciences, Fisheries and Economics, Breivika, 9037 Tromso, Norway, margrethe.aanesen@uit.no; phone +47 77646392 


\section{Sequential Bargaining, External Effects of Agreement, and Public Intervention}

\section{Introduction}

When the iron curtain fell in 1989, large differences in the state of the environment between former eastern and western European countries were disclosed. For western European governments neighbouring eastern European countries this came as no surprise, as the old and dirty energy and manufacturing plants along the eastern side of the border had been the source of a continuous stream of transboundary polluting emissions for decades (www.amap.no, www.eea.europa.eu).

From an economic point of view, the problem with transboundary pollution is that due to different jurisdictional areas, parts of the environmental damages caused by the pollution are not counted when abatement efforts are considered. Failing to internalise negative externalities implies that profitable abatement efforts are not implemented, which in turn gives welfare losses. When this situation continues, the welfare loss aggregates and may take on substantial magnitudes.

The use of financial support (subsidies) to foreign plants to motivate them to invest in new technology and thus step up the conversion process to more environmental friendly production seems to be one of very few measures a government, experiencing transboundary pollution, has to internalise these externalities. Whether this contributes to a quicker and more efficient implementation process for cleaner technology is the focal question of this paper. We analyse the implementation of environmental friendly technology in polluting 
plants as a sequential bargaining game between a buyer and a seller of technology. A government, representing a country which is negatively affected by the production in the polluting plant, intervenes and offers a subsidy, which is subtracted from the seller's price if agreement is reached. Formally, this is a 3player sequential bargaining game where the buyer is a (east European) polluting plant and the seller is a (multinational) supplier of such technology. The technology in question is common, and thus we assume the seller's costs to be common knowledge. Due to the tradition which developed in former eastern European countries of keeping information secret we assume that the buyer's valuation of environmental friendly technology is private information. As the economic standard in the eastern part of Europe is lower than in the western part, the valuation does not necessarily exceed the costs of the technology. The government is foreign to both traders and has no interests in the trade except from the environmental side (internalising the externality). As the size of the externalities is publicly documented, we assume that the government's valuation of trade is common knowledge. The government involved is only concerned with social welfare. However, we must hold open for the possibility that other governments will prioritize differently and not continue the negotiations if they come to power. Hence, we assume a finite bargaining game.

We show that the government's valuation of trade must exceed the upper limit of the buyer's valuation net of the seller's costs before it is optimal to intervene with a subsidy. Given intervention, this will step up the trading process when the agents are perfectly patient. With impatient agents, intervention only conditionally steps up the trading process. Given intervention, the possibility that no trade takes place, although it is profitable, is reduced. 
Significant welfare losses due to transboundary pollution may be one reason for the involvement of Scandinavian and other European governments in environmental protection in neighbouring countries. The Arctic Monitoring and Assessment Programme (AMAP) has since the early 1990s documented severe transboundary environmental degradation in the border area between Norway, Finland, and Russia (www.amap.no). Smith-Sivertsen (2000) documented poor health conditions on the Russian and Norwegian side of the same border. Both characteristics are ascribed to the huge emissions of sulphur dioxide from an old and obsolete nickel plant and a few other mineral processing plants on the Russian side of the border. This has caused Finland and Norway to repeatedly suggest efforts to reduce the emissions, and the most concrete proposal is financial support to cover parts of the costs of renovating the nickel plant (Aanesen 2006a).

Another example is Austria. Located in the heart of Europe and bordering three eastern European countries; Slovenia, Slovakia, and the Czech Republic, it has experienced large influxes of transboundary pollution (www.eea.europa.eu). In 1992 the Austrian government set up the East-Ecology Fund, which has supported sulphur dioxide reducing and energy saving projects located in the mentioned neighbouring countries along the border to Austria. Support has been in the form of grants to the projects, which cover about $10 \%$ of the project costs (Jackson et al 2001).

A third example is the involvement of Sweden and Denmark in environmental projects in the Baltic countries. Though not having common physical borders, all countries border the Baltic sea, a sea for which the EU has initiated an action plan to restore the environmental standard (Jackson et al 2001). 
One class of bargaining games is characterised by a possibility for no gains from trade (the no-gap case). Under asymmetric information and given that the buyer may take a continuum of types, these games have a unique perfect Bayesian equilibrium (Fudenberg and Tirole 1983). When there is a finite number of periods and a delay between the offers, the equilibrium price only asymptotically approaches the seller's reservation price, and the seller uses time as a signal to screen the buyer. ${ }^{1}$ Hence, ex ante agreement is only reached with a delay, and the equilibrium is inefficient (Sobel and Takahashi 1983, Caparros et al 2004). When the private information is represented by a two-point distribution, a solution is always reached within the first two periods, and the equilibrium is efficient (Fudenberg and Tirole 1993, Chambers and Jensen 2002, Caparros et al 2004). An infinite bargaining horizon tends to prolong the delay in trade, but also to secure an efficient bargaining outcome (Sobel and Takahashi 1983, Fudenberg et al 1985). Ausubel and Deneckere $(1989,1993)$ derive an efficient mechanism for sequential bargaining games with one-sided (1989) and two-sided (1993) asymmetric information and offers. However, only with an infinite horizon does this mechanism prove efficient, as the price only asymptotically reaches the seller’s reservation price.

There are a few papers on public intervention in bargaining games. Spencer and Brander (1983) analyse public intervention in the form of $R \& D$ and export subsidies to domestic industries operating in imperfect international markets. Aanesen (2006b) discusses the effects of public intervention in a 'take-it-or-leave-

\footnotetext{
${ }^{1}$ Without restrictions on how fast offers can be forwarded, agreement will be reached almost instantaneously and at a price equal to the seller's reservation price (Gul and Sonnenschein 1986).
} 
it' transaction situation, where the interests of the intervening government may be due to both industrial and environmental interests. Both papers, however, use a static, two stage bargaining model. To our knowledge, the issue of public intervention in sequential bargaining with one-sided asymmetric information has not previously been addressed.

The paper is organised as follows: Section Two presents the intervention model, derives a perfect equilibrium where the optimal subsidy is part of the equilibrium, and analyses the effects of intervention on the equilibrium characteristics. Section Three discusses the model results in the light of the empirical examples above, and Section Four concludes.

\section{A sequential bargaining model with public intervention}

\subsection{The model}

A monopolist seller of environmental friendly technology faces a single, privately informed buyer, whose valuation of the good, $V$, is continuously and uniformly

distributed on $[\underline{V}, \bar{V}]$, and for simplicity and without consequences for the results we set $\underline{V}=0$. Seller's costs (reservation price), $C$, is common knowledge, and we assume $C>0$. Due to a positive valuation of trade, a third agent, government, may intervene with a subsidy, and its reservation value, $W$, is common knowledge.

We assume a two period trading process, where each period has two stages. At the first stage, the government and the seller sequentially forward their offers, and the government's subsidy, if any, is subtracted from the seller's price to give the price the buyer faces (net price). The buyer does nothing. At the second stage, the buyer 
either accepts or rejects the net price, and the seller and the government do nothing. Being perfectly informed and rightly assuming the net price forwarded in each period, the buyer decides the optimal period to buy, and waiting is costly for all agents. At the first stage of the game, the government is the leader. Other sequences are also possible, but here we follow Spencer and Brander (1983) arguing that: 1) It is both costly and time consuming for a government to decide on whether to intervene in a bargaining process between private agents and on the optimal subsidy, and this inflexibility provides a credible commitment and places the government naturally in a leadership role. 2) A government needs to maintain a reputation for being predictable when it comes to its environmental policy, which also naturally places it in a leadership role.

If intervention and trade take place in period $n$, the payoff to the seller, the buyer and the government respectively are given by $\delta^{n-1}\left(p_{n}-C\right), \delta^{n-1}\left(V-p_{n}+x_{n}\right)$, and $\delta^{n-1}\left(W-x_{n}\right)$, where $\delta$ is the common discount factor, $p_{n}$ and $x_{n}$ are the price and the subsidy respectively, offered in period $n$, and $n \in\{1,2\}$. The government's payoff function needs some explanation. As argued above, situations exist where the main aim of a government's intervention is to reduce pollution (internalising externalities), and where it has no other (strategic) interests. Such a framework departs from other contributions to the literature on public intervention in bargaining games (Spencer and Brander 1983, Laplante 1990, Herander 1995), where the government is domestic to the seller and thus has strategic interests, often expressed in terms of the profit of one or both traders. As the government in our model is foreign to both trading partners, its payoff only consists of $W$, which represents the government's valuation of the externality. 
If we put no restrictions on the sign of the intervention, (a negative subsidy represents a tax), the government faces a choice between two strategies. On one hand, it may realise $W$ by offering a subsidy which reduces the buyer's price and increases the probability for trade. On the other hand, it may extract the surplus from trade by taxing trade, which reduces the probability for trade. ${ }^{2}$ However, the fact that a government does not have the legal rights to tax companies registered in other countries excludes the possibility of a negative subsidy.

Restricting intervention to subsidisation implies $x_{n} \geq 0, n=1,2$. Let $x_{n}{ }^{S}, n=1,2$ denote the subsidy along the unrestricted equilibrium path, i.e. when the intervention is not restricted to subsidisation. Then, along the equilibrium path $x_{n}{ }^{S}$ is strictly increasing over time such that $x_{1}^{S}>0 \Rightarrow x_{2}{ }^{S}>0 .{ }^{3}$ However, its converse is not necessarily true, implying that along the unrestricted equilibrium path we may have a situation which involves intervention in the second period, but not in the first. Such a strategy is problematic. We have argued that the government naturally acts as a Stackelberg leader in an intervention game, which presupposes that it is present during the whole negotiation process and does not walk in and out of the negotiations, depending on whether it is in its interest to offer a subsidy or not. Hence, we restrict the government's set of strategies to either intervene with the intention to offer a subsidy in both periods or not intervene at all. Formally, this implies that the restricted equilibrium subsidy, $x_{n}{ }^{*}, n=1,2$, is given by

\footnotetext{
${ }^{2}$ This is an optimal strategy in the case of low seller's costs, which implies a low price and thus an ex ante high probability for trade, and in the case of low externalities.

${ }^{3}$ There is one exception when $\delta=1$. Then the government may reduce the second period subsidy.
} 


$$
\begin{aligned}
& x_{1}^{*}=\left\{x_{1}^{s}, 0\right\} \\
& x_{2}{ }^{*}=\left\{x_{2}{ }^{s}, 0\right\}, x_{1}^{*}>0 \\
& x_{2}{ }^{*}=0 \quad \text { i } x_{1}^{*}<0
\end{aligned}
$$

In the case of no trade, we normalise the payoff to the agents to zero. Trade may take place without intervention, and in this case, the payoff to the agents is given above when $x_{n}=0, n=1,2$. The government's payoff in this case equals $\delta^{n-1} W$, which is at least as high as under intervention. The reason why the government still may be interested in intervening is that intervention increases the probability for trade, and thus for $W$ to be realised. Eliminating the possibility for negative prices, the net price $\pi_{n}$ is given by $\pi_{n}=\max \left\{p_{n}-x_{n}, 0\right\}, n=1,2$. In order to remain in the no-gap case, we assume that $C-W \geq \underline{V} \equiv 0$.

\subsection{A perfect equilibrium in a sequential bargaining model without} intervention

Sobel and Takahashi (1983, Theorem 2 p 217) show that with no intervention, there exists a no-commitment equilibrium. ${ }^{4}$ When $C>0$, this is given by $P_{1}(\delta)=2\left[\left(1-\frac{\delta}{2}\right)^{2}+\left(1-\frac{\delta}{2}-\frac{\delta^{2}}{4}\right) C\right](4-3 \delta)^{-1}$

$P_{2}(\delta)=\frac{1}{2}[2-\delta+(6-5 \delta) C](4-3 \delta)^{-1}$

$$
S(\delta)=[2-\delta+2(1-\delta) C](4-3 \delta)^{-1}
$$

\footnotetext{
${ }^{4}$ A no-commitment equilibrium assumes that the agents at the start of each period optimise their continuation payoff (the payoff from that period and onward). In contrast, a commitment equilibrium assumes that the agents optimise for the whole game in the first period, and then
} 
where (2) and (3) give the price offered in the first and second period respectively, and $S$ is the cutoff value, which defines the lowest valuation buyer who will buy in the first period. This perfect Bayesian equilibrium is stationary, and as part of the equilibrium, the buyer's behaviour is characterised by the skimming property (Fudenberg and Tirole 1993, p 407). $S>P_{1}>P_{2}$ implies a positive probability for trade in both periods. Buyer's expectation about future prices is rational, and the seller becomes more pessimistic as to the beliefs about the buyer's valuation when an offer is rejected (Fudenberg and Tirole 1983). $P_{2}(\delta)>C$, and thus the equilibrium is ex ante inefficient.

\subsection{The perfect equilibrium under intervention}

Introducing the possibility for intervention, we look for perfect Bayesian equilibrium strategies for the seller and the government, and where the buyer's behaviour is characterised by the skimming property. The government is restricted to either subsidise trade in both periods or not intervene. By backward induction, the last period can be analysed as a static maximisation problem, where the government, in the role of a Stackelberg leader, maximises the final period payoff taking into consideration the seller's reaction function. The objective functions are given in the appendix. The last period equilibrium solution for the subsidy, the seller's price and the net price are given by

$$
\begin{array}{ll}
x_{2}{ }^{*}=\left\{\frac{C+W-T}{2}, 0\right\}, \mathrm{x}_{1}^{*}>0 \\
x_{2}{ }^{*}=0 \quad \text { otherwise }
\end{array}
$$


$p_{2}^{*}=\frac{3 C+W+T}{4}$

$\pi_{2}^{*}=\max \left\{\frac{C-W+3 T}{4}, 0\right\}$

where $T$ is the cutoff value under intervention.

The seller's and the government's first period continuation payoffs respectively are given by

$U_{S}(W, C, \delta)=\left[\left(p_{1}-C\right)\left(\frac{\bar{V}-T}{\bar{V}}\right) \bar{V}+\delta\left(\left(p_{2}-C\right)\left(\frac{T-p_{2}+x_{2}}{T}\right) T\right]\right.$
$U_{G}(W, C, \delta)=\left[\left(W-x_{1}\right)\left(\frac{\bar{V}-T}{\bar{V}}\right) \bar{V}+\delta\left(\left(W-x_{2}\right)\left(\frac{T-p_{2}+x_{2}}{T}\right) T\right]\right.$

In the first period, the government rightly anticipates the cutoff value set by the seller, ${ }^{5}$ and inserting for this in (9), it maximises its continuation payoff with respect to the subsidy. The seller decides upon a cutoff value, i.e. the lowest valuation buyer to sell to in the first period. It does this by maximising its continuation payoff given by (8) when $p_{1}$ is substituted by the reaction function given in (11) below, with respect to the cutoff value.

Both seller and government take into consideration the buyer's decision strategy, which is characterised by the skimming property. This states that higher valuation types of buyers buy earlier because they lose more by postponing consumption. The buyer uses the first offer to make predictions about future prices, and in a perfect equilibrium, these predictions are rational. Let $p_{1}$ and $x_{1}$ be the price and the subsidy offered in the first period. The skimming property implies that a buyer 
with valuation $V=T$ will accept the net price $\pi_{1}=p_{1}-x_{1}$ in the first period when it expects a net price equal to $\pi_{2}=p_{2}(T)-x_{2}(T)$ in the last period if

$$
T-\left(p_{1}-x_{1}\right) \geq \delta\left(T-\left(p_{2}-x_{2}\right)\right)
$$

Substituting $p_{2}$ and $x_{2}$ in (10) by the price and the subsidy along the unrestricted equilibrium paths, $x_{n}{ }^{S}, n=1,2$, and solving for $p_{1}$ and $x_{1}$ when assuming that (10) is fulfilled with equality, gives the following reaction functions for the first period price and subsidy in the intervention model

$$
\begin{aligned}
& p_{1}{ }^{R}=\left(1-\frac{\delta}{4}\right) T+\frac{\delta}{4}(C-W)+x_{1} \\
& x_{1}{ }^{R}=-\left(1-\frac{\delta}{4}\right) T-\frac{\delta}{4}(C-W)+p_{1} .
\end{aligned}
$$

Inserting for the optimal subsidy and the optimal cutoff value in (11) yields the equilibrium first period price. The restricted equilibrium solution to the endogenous variables is given by ${ }^{6}$

$$
\begin{aligned}
& T^{*}(\delta)=\alpha(\delta) \bar{V}+\beta(\delta)(C-W) \\
& x_{1}^{*}(\delta)=\{\gamma(\delta)(C-\bar{V})+\varepsilon(\delta) W, 0\} \\
& p_{1}^{*}(\delta)=\phi(\delta) \bar{V}+\gamma(\delta) C+\eta(\delta) W \\
& \pi_{1}^{*}(\delta)=\max \{\kappa(\delta) \bar{V}+\mu(\delta) C+\theta(\delta) W, 0\} .
\end{aligned}
$$

\footnotetext{
${ }^{5}$ The seller's cutoff value is formulated as a reaction to the government's subsidy.

${ }^{6}$ The full expressions for the parameters are given in the appendix.
} 
Having ruled out the possibility for a negative subsidy, a necessary condition for the solution given by (13)-(16) to constitute an equilibrium, is $\forall x_{n}{ }^{*}>0, U_{G}\left(C, W, \delta, x_{n}{ }^{*}\right)>U_{G}(C, W, \delta, 0)$. Applying a no-commitment equilibrium concept, this implies that the aggregate of the two (discounted) period payoffs under intervention must exceed the corresponding aggregate when not intervening. The condition for this to hold is given in the appendix. On the other hand, $\forall x_{n}{ }^{*}<0, U_{G}\left(C, W, \delta, x_{n}^{*}\right)>U_{G}(C, W, \delta, 0)$ can also be shown to hold, implying that intervening with a tax is more profitable than not intervening. Thus, when taxation is not an option, it is necessary to explicitly rule out this possibility, otherwise it would be part of the perfect equilibrium in a sequential bargaining model with intervention.

\section{Proposition 1}

When $0 \leq \delta<1, C+W \geq \bar{V}$ is a sufficient condition for intervention. When $\delta=1, C+W>\bar{V}$ is a necessary and sufficient condition for intervention.

\section{Proof}

The first period equilibrium subsidy is given by $x_{1}{ }^{*}(\delta)=\gamma(\delta)(C-\bar{V})+\varepsilon(\delta) W$. It can be shown that $\forall \delta \in[0,1], \gamma(\delta)+\varepsilon(\delta)=1$. Hence, the first period subsidy is a weighted sum of the seller's and the government's reservation value subtracted a term proportional in the buyer's upper valuation limit. Along the equilibrium path the subsidy is continuously increasing in $\mathrm{C}, \mathrm{W}$ and $\delta$. The conjunction of $\delta=1$ and $C+W=\bar{V}$ yields $x_{1}{ }^{*}=0$, hence with perfectly patient agents, it must be the case that $C+W>\bar{V}$ for intervention to take place. As the subsidy increases over 
time, $C+W>\bar{V}$ is a sufficient condition for $x_{2}{ }^{*}>0$. For $0 \leq \delta<1, x_{1}{ }^{*}>0$ when $C+W=\bar{V}$, which means that $C+W \geq \bar{V}$ is a sufficient but not a necessary condition for intervention in the first period, as $C+W$ slightly below $\bar{V}$ provides a positive subsidy in the first period.

QED

Reformulating the condition for intervention yields $\bar{V}-C \leq W$. Hence, when the highest possible "private” profit from trade is high, the externalities must also be high for intervention to take place. In this situation, the probability for trade without intervention is high, and then the externalities must be high in order to justify intervention. On the other hand, when the gap between the buyer's upper valuation limit and the costs is small, the probability for trade is small. Then intervention makes a more substantial difference on whether trade will take place or not and can thus be justified even if the externalities are limited. Independent of the magnitude of $\mathrm{C}$ and $\mathrm{W}$, the first period subsidy takes its highest value when $\delta=1$. The fact that perfectly patient agents, including the government, yield the highest subsidy may explain why the condition for intervention is stronger when $\delta=1$

The cutoff value, $T$, indicates the buyer with the lowest valuation who possibly will buy in the first period, and the lower the cutoff value is, the higher is the probability that trade takes place in the first period. The delay in trade is reduced due to intervention when $T *(\delta)<S(\delta)$, where $S(\delta)$ is given in (4).

\section{Proposition 2}


When $\delta=1$, intervention always reduces delays in trade, whereas when $0 \leq \delta<1$, intervention reduces delays in trade when $C+W>\bar{V}$.

\section{Proof}

Using (13) and (4), $T^{*}(\delta)<S(\delta)$ implies that

$\alpha(\delta) \bar{V}+\beta(\delta)(C-W)<l(\delta) \bar{V}+j(\delta) C$

where $\quad l(\delta)=(2-\delta)(4-3 \delta)^{-1}, j(\delta)=2(1-\delta)(4-3 \delta)^{-1}$. All parameter expressions are positive and continuous in $\delta$, and $\forall \delta, \alpha(\delta)+\beta(\delta)=l(\delta)+j(\delta) \equiv 1$, which implies $\quad \alpha(\delta)-l(\delta)=j(\delta)-\beta(\delta)$. Hence, (17) can be reformulated to give

$\frac{\alpha(\delta)-l(\delta)}{\beta(\delta)}<\frac{W}{\bar{V}-C}$

We restrict the proof to the case when $C<\bar{V}$, which secures that there is a positive probability for trade also without intervention. It can be shown that $\forall \delta \in[0,1], \frac{\alpha(\delta)-l(\delta)}{\beta(\delta)} \leq 1$ (see figure A1 in the appendix). Hence, a sufficient condition for (17') to be fulfilled is that the right hand side exceeds one. This is fulfilled when $W>(\bar{V}-C)$, or when $C+W>\bar{V}$. Hence, when $\delta=1$, intervention always reduces delays in trade, as the condition for intervention in this case is $C+W>\bar{V}$. When $0 \leq \delta<1, C+W \geq \bar{V}$ is a sufficient condition for intervention, and then there are situations, i.e. when $C+W=\bar{V}$, where intervention takes place, but delays in trade are not necessarily reduced.

QED 
As the condition for intervention is stronger with perfectly patient agents, it should be no surprise that in this case, intervention always reduces delays in trade, whereas it only conditionally reduces delays in trade with impatient agents.

In the last period, all buyers with valuation equal to or above the net price will buy. As long as the net price exceeds the seller's reservation price net of the externalities, the equilibrium is ex ante inefficient. Reducing the last period net price increases the probability for trade and thus reduces the equilibrium inefficiency. Intervention reduces the last period net price when $\pi_{2}{ }^{*}(\delta)<P_{2}(\delta)$, where $P_{2}(\delta)$ is given in (2).

\section{Proposition 3}

Whenever intervention is optimal for the government, the equilibrium intervention always reduces the equilibrium inefficiency.

\section{Proof}

$\pi_{2}^{*}(\delta)<P_{2}(\delta)$ implies that

$$
\rho(\delta) \bar{V}+\sigma(\delta)(C-W)<v(\delta) \bar{V}+w(\delta) C,
$$

where we have inserted for $T^{*}(\delta)$ in (7) to get $\rho(\delta)$ and $\sigma(\delta)$ (see the appendix for the parameter expressions). All parameter expressions are positive and continuous in $\quad \delta, \quad$ and $\quad \forall \delta, \rho(\delta)+\sigma(\delta)=v(\delta)+w(\delta) \equiv 1$, which implies $\rho(\delta)-v(\delta)=w(\delta)-\sigma(\delta)$. Using these characteristics and reorganising yields

$$
\frac{\rho(\delta)-v(\delta)}{\sigma(\delta)}<\frac{W}{\bar{V}-C}
$$


We restrict the proof to the case $C<\bar{V}$. It can be shown that $\forall \delta, \frac{\rho(\delta)-v(\delta)}{\sigma(\delta)}<1$ (see figure A2 in the appendix). Hence, for intervention to reduce the equilibrium inefficiency it suffices that the right hand side of (18') is equal to or above 1 , or $C+W \geq \bar{V}$. Independent of the discount factor, this is always fulfilled when the condition for intervention is fulfilled.

QED

We have shown that the equilibrium intervention always reduces the equilibrium inefficiency, whereas it only conditionally reduces delays in trade. These results are due to the reinforcing dynamic effect of the subsidy. The subsidy increases over time. The delay in trade reduces when the cutoff value reduces, which in turn reduces in the first period subsidy. The equilibrium inefficiency reduces in the last period net price, which in turn reduces in the second period subsidy. Hence, the later in the bargaining process an intended effect of the intervention may occur, the more likely it is that the effect actually takes place.

\section{The effects of intervention}

In some respects, intervention alters the perfect equilibrium of the original model, whereas other characteristics remain the same. When the agents are impatient, there is a trade-off between buying in an early period at a high price and buying later at a lower price. With perfectly patient agents this trade-off does not exist, as a perfectly patient buyer is indifferent with respect to when to buy. Hence, in the original model, when the buyer becomes perfectly patient, the same price is offered in each period and the buyer buys in the first period or never. Also under intervention, the net price remains the same when the agents are perfectly patient. 
However, this constant price now blurs totally different strategies for the seller and the government. The government exploits its power as Stackelberg leader and decreases the subsidy over time. In isolation, this contributes to decreasing the probability for trade. The government can do so because it knows the optimal response of the seller. The seller, in turn, knows the optimal net price to offer a perfectly patient buyer and has no better option than fixing its price in order to ensure that this net price is offered.

When the iron curtain fell, a large gap in the economic standard between the eastern and the western part of Europe was revealed. In this situation, both the east European governments and the populations were more impatient to increase the economic wealth than to improve the state of the environment (Ready 2002). Hence, it is acceptable to assume that the buyer, i.e. a polluting plant in an east European country, had low (no) time costs when it came to environmental efforts. Assuming a perfectly patient seller, this is a beneficial situation for a perfectly patient government to intervene, as it would be able to exploit its first mover advantage and "force" the seller to secure that the optimal net price is offered. Hence, the results of the intervention model indicate that governments intervening with a subsidy in a bargaining process with perfectly patient traders probably also have very low (no) time costs. In the transboundary pollution case between Norway, Finland and Russia the negotiations took place over nearly a decade. The intervention model results show that as the common time costs increase, both the government and the seller are worse off the longer the negotiations last. Hence, given low time costs for the buyer, it is reasonable to assume low time costs also for the governments (in Norway and Finland) and the seller, as with high time costs staying in the negotiations would be costly. 
On the other hand, as one of the intended and realised effects of intervention is to reduce delays in trade, one can argue that the governments in this situation would be rather impatient to reach results in order to realise welfare gains.

Intervention may affect the equilibrium price path of the seller in two obvious ways: 1) increase the price, 2) increase the probability of trade. A closer inspection of the restricted equilibrium price path under intervention discloses a third option; 3) a decrease in the seller's price. This latter option is an equilibrium strategy in both periods when the condition for intervention is only tightly fulfilled, i.e. $\bar{V}-C$ is close to $W$, and when the time costs are low, i.e. $\delta \approx 1$. Under these conditions, the government may not be interested in intervening if the seller confiscates a part of the subsidy, as the increase in payoff in form of increased probability for trade would then be too low. Hence, by lowering the price the seller directly contributes to increasing the probability for trade.

When the condition for intervention is fulfilled with a margin, i.e. $\bar{V}-C<W$, the seller's equilibrium strategy implies to confiscate a part of the subsidy, but still ensure that the probability for trade increases compared to when there is no intervention. The higher the time costs are, the higher is the share of the subsidy the seller confiscates and the lower is the increase in the probability for trade due to intervention.

Low seller's costs and low externalities hinder intervention. Low seller's costs imply a low price and in turn a high ex ante probability that trade will take place even without intervention. Hence, the contribution of the subsidy to increase the 
probability for trade is limited, and the costs of the subsidy exceed the increase in government's payoff due to increased probability for trade. Similarly, low externalities restrict the size of the subsidy and thus the reduction in the net price due to intervention. This in turn restricts the increase in the probability for trade to take place due to intervention. Regarding the transboundary pollution in the Finnish-Norwegian-Russian border area it is a fact that the modernisation of the obsolete and polluting plant would be costly (Kola Science Centre 1992) and that the externalities were large (www.amap.no), both of which increases the probability for intervention.

\section{$4 \quad$ Discussion and Conclusions}

Transboundary pollution causes an externality which is often not internalised when decisions regarding abatement efforts are taken. This leads to inefficient adjustments with respect to abatement efforts for the affected area irrespective of borders. In this paper we have demonstrated that public intervention in a sequential bargaining game reduces such inefficiencies, i.e. it conditionally reduces delays in trade and it with certainty increases the probability that abatement efforts are implemented when this is profitable. Our results indicate that the conjunction of a low (upper limit of) buyer's valuation of trade, high seller's costs and low (common) time costs makes intervention attractive for a government, and thus increases the probability for intervention, and we argue that at least the two former characteristics have been present in cases of public intervention to promote environmental protection in Europe the last decades.

Examples from Europe show that in situations with transboundary pollution and not internalised externalities, the negatively affected agents have intervened with a 
subsidy which is realised if the polluter meets an agreement about trade with a seller of environmental friendly technology. The most prominent example is probably the Finnish and Norwegian governments intervening in the process of modernising the obsolete and very polluting nickel plant in the Russian town Nikel. Although an agreement about reconstructing the plant and thus reducing the sulphur dioxide emissions by $90 \%$ was signed in 2001, the reconstruction is still not completed. However, a former Norwegian minister of the Environment underlined that without the Norwegian involvement the process of reducing the sulphur emissions from the nickel plant would probably not have been on the agenda at all (Norwegian Ministry of the Environment, 2007). Also, several projects under the joint implementation mechanism (JI, now clean development mechanism, CDM) in the Kyoto protocol have come into force, and among these are projects where west European governments have contributed financially in order to promote the upgrading of obsolete and polluting energy supply systems in bordering east European countries (Jackson et al 2001). Although difficult to verify, it is realistic to assume that many of these plants would not have been upgraded at that time, or at all, without the public intervention from west European governments.

Extensions of the model presented in this paper could answer the new questions these empirical cases raise. First, the government's payoff only encompasses aspects of social welfare (internalising externalities). This was to concentrate on the environmental aspect of the intervention, not including strategic intentions such as the promotion of domestic industries. However, aspects of the empirical examples we rest on suggest that the intervening governments may, at some stages, also have had strategic interests. This probably was the case for the 
Finnish government, which withdrew its grant to the reconstruction of the nickel work in the Russian town Nikel when the offer of more environmental friendly technology, supplied by a consortium led by the Finnish company Outokumpu, was rejected. It is of interest to analyse how an extension of the government's interests to include also strategic interests will affect the results presented in this paper.

Admittedly, simplifying the model by assuming a common discount factor has consequences for the results. In the original model, Sobel and Takahashi (1983, p 417) show that the seller is made better off when the buyer's time costs increase, whereas the buyer is made worse off when the seller's time costs decrease. It is of interest to explore further how varying the time costs between the agents affects the results of the intervention model.

Finally, the strategic interaction between the government and the seller in the first stage is defined exogenously and assumed to be a Stackelberg game with the government as the leader. This is in accordance with previous literature (Spencer and Brander 1983), and other empirical facts also support this assumption. However, other types of the first stage game are possible, and it might also be endogenous to the model which game the seller and the government plays when fixing the price and the subsidy in the initial phase. Such changes of bargaining procedure might well change the results of the analysis. 


\section{Appendix}

In the last period, the seller, being the follower in a Stackelberg game where the government is the leader, faces the following maximisation problem $\max _{p 2}\left[\left(p_{2}-C\right)\left(\frac{T-p_{2}+x_{2}}{T}\right) T\right](\mathrm{A} 1)$, which gives the following reaction function $p_{2}{ }^{R}=\frac{x_{2}+W+T}{2}$ (A2). The optimal subsidy for the government to set in the last period, given that the seller sets the price $\mathrm{p}_{2}$, is given by $\max _{x 2}\left[\left(W-x_{2}\right)\left(\frac{T-p_{2}+x_{2}}{T}\right) T\right]$ (A3). Inserting $p_{2}{ }^{R}$ for $p_{2}$ in (A3) and solving the restricted optimisation problem gives (5). Inserting for (5) in (A2) gives (6).

In the first period, the seller first fixes a cutoff value and then decides the optimal price. The cutoff value is found by maximising the continuation payoff in (8) when having inserted for the last period equilibrium expressions and substituted $p_{1}$ by the reaction function in (11). This leads to the following expression for the seller's continuation payoff:

$U_{s}(W, C, \delta)=\left[\left(\left(1-\frac{\delta}{4}\right)(T-C)+\frac{\delta}{4} W+x_{1}\right)(\bar{V}-T)+\delta\left(\frac{T+W-C}{4}\right)^{2}\right]$

Maximising (A4) with respect to $T$ gives the optimal cutoff value as a reaction to the subsidy, and this is given by $T^{R}=\left(\left(1-\frac{\delta}{4}\right) \bar{V}+\left(1-\frac{3 \delta}{8}\right) C+\frac{3 \delta}{8} W-x_{1}\right)\left(2-\frac{5 \delta}{8}\right)^{-1}$ (A5). 
The government's continuation payoff, when inserting for the last period equilibrium variables and the cutoff value, is given by

$$
U_{G}=\left[\left(W-x_{1}\right)\left(\frac{\left(1-\frac{3 \delta}{8}\right)(\bar{V}-C)-\frac{3 \delta}{8} W+x_{1}}{\left(2-\frac{5 \delta}{8}\right)}\right)+\frac{\delta}{8}\left(\frac{\left(1-\frac{\delta}{4}\right)(\bar{V}-C)+\left(2-\frac{\delta}{4}\right) W-x_{1}}{\left(2-\frac{5 \delta}{8}\right)}\right)^{2}\right]
$$

The government maximises its continuation pay-off with respect to $x_{1}$ and takes into consideration the seller's prising strategy (optimal cutoff value). This yields (14). Inserting for (14) in (A5) yields (13). Finally, inserting for (13) and (14) in (11) yields (15).

The parameter expressions in (13)-(16) are:

$$
\alpha(\delta)=\frac{24-\frac{29 \delta}{2}+\frac{35 \delta^{2}}{16}}{(16-6 \delta)\left(2-\frac{5 \delta}{8}\right)} \quad \beta(\delta)=\frac{8-\frac{15 \delta}{2}+\frac{25 \delta^{2}}{16}}{(16-6 \delta)\left(2-\frac{5 \delta}{8}\right)}
$$

$\gamma(\delta)=\frac{8-\frac{9 \delta}{2}+\frac{11 \delta^{2}}{16}}{(16-6 \delta)} \quad \varepsilon(\delta) \frac{8-\frac{3 \delta}{2}-\frac{11 \delta^{2}}{16}}{(16-6 \delta)}$

$$
\begin{aligned}
& \phi(\delta)=\frac{8-\frac{13 \delta}{2}+\frac{26 \delta^{2}}{16}+\frac{15 \delta^{3}}{128}}{(16-6 \delta)\left(2-\frac{5 \delta}{8}\right)} \quad \gamma(\delta)=\frac{24+\frac{17 \delta}{2}-\frac{115 \delta^{2}}{8}+\frac{375 \delta^{3}}{128}}{(16-6 \delta)\left(2-\frac{5 \delta}{8}\right)} \\
& \eta(\delta)=\frac{8-\frac{61 \delta}{2}+\frac{305 \delta^{2}}{16}-\frac{305 \delta^{3}}{128}}{(16-6 \delta)\left(2-\frac{5 \delta}{8}\right)}
\end{aligned}
$$




$$
\begin{aligned}
& \kappa(\delta)=\frac{24-\frac{41 \delta}{2}+\frac{93 \delta^{2}}{16}-\frac{70 \delta^{3}}{128}}{(16-6 \delta)\left(2-\frac{5 \delta}{8}\right)} \quad \mu(\delta)=\frac{8+\frac{11 \delta}{2}-\frac{297 \delta^{2}}{16}+\frac{430 \delta^{3}}{128}}{(16-6 \delta)\left(2-\frac{5 \delta}{8}\right)} \\
& \theta(\delta)=\frac{-8-\frac{45 \delta}{2}+\frac{230 \delta^{2}}{16}-\frac{250 \delta^{3}}{128}}{(16-6 \delta)\left(2-\frac{5 \delta}{8}\right)}
\end{aligned}
$$

The parameter expressions in (18) are:

$$
\begin{aligned}
& \rho(\delta)=\frac{18-\frac{87 \delta}{8}+\frac{105 \delta^{2}}{64}}{(16-6 \delta)\left(2-\frac{5 \delta}{8}\right)}, \sigma(\delta)=\frac{14-\frac{89 \delta}{8}+\frac{135 \delta^{2}}{64}}{(16-6 \delta)\left(2-\frac{5 \delta}{8}\right)}, \\
& v(\delta)=\frac{2-\delta}{2(4-3 \delta)}, w(\delta)=\frac{6-5 \delta}{2(4-3 \delta)} .
\end{aligned}
$$

The continuation payoff to the government by intervention exceeds the continuation payoff without intervention when

$$
\left(W-x_{1}\right)\left(\frac{\bar{V}-T}{\bar{V}}\right) \bar{V}+\delta\left(W-x_{2}\right)\left(\frac{T-p_{2}-x_{2}}{T}\right) T>W\left(\frac{\bar{V}-S}{\bar{V}}\right) \bar{V}+\delta W\left(\frac{S-P_{2}}{S}\right) S
$$

Reformulated (A7) can be expressed as

$$
W(S-T)(1-\delta)+\delta W\left(P_{2}-p_{2}+x_{2}\right)+x_{1}(T-\bar{V})+\delta x_{2}\left(p_{2}-x_{2}-T\right)>0\left(\mathrm{~A}^{\prime}\right)
$$

By inserting for the endogenous variables as given by (13)-(16) and the parameter expressions above in (A7'), this inequality can be expressed as a function of the exogenous variables $W, \bar{V}$, and $\delta$. However, due to its complexity and the fact that the three exogenous variables may take a range of values, it is not possible to pin down to an explicit, unambiguous condition for the inequality in (A7') to be fulfilled. We thus have tested the inequality numerically for all relevant 
combinations of variable values on $W, \bar{V}$, and $\delta$, and by this can show that the inequality always holds.

Figure A1 The left hand side of (17') as a function of the discount factor $\delta$

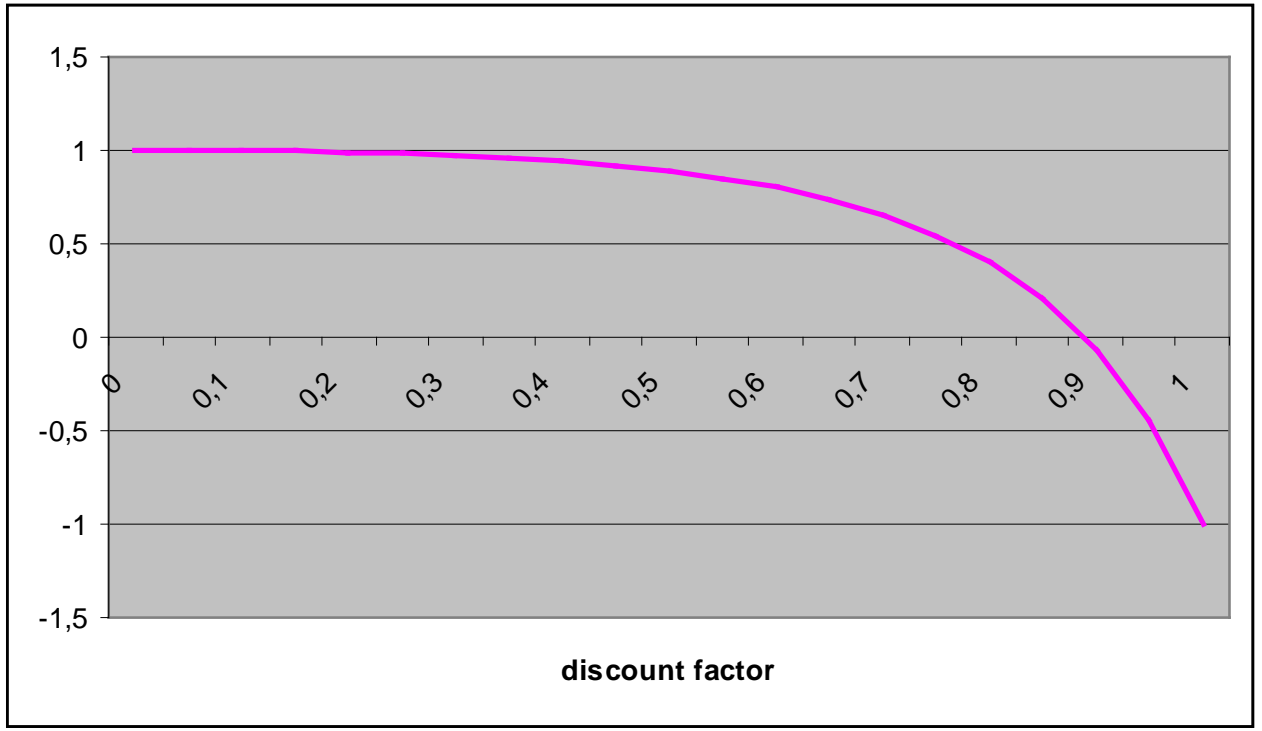

Figure A2 The left hand side of (18') as a function of the discount factor $\delta$

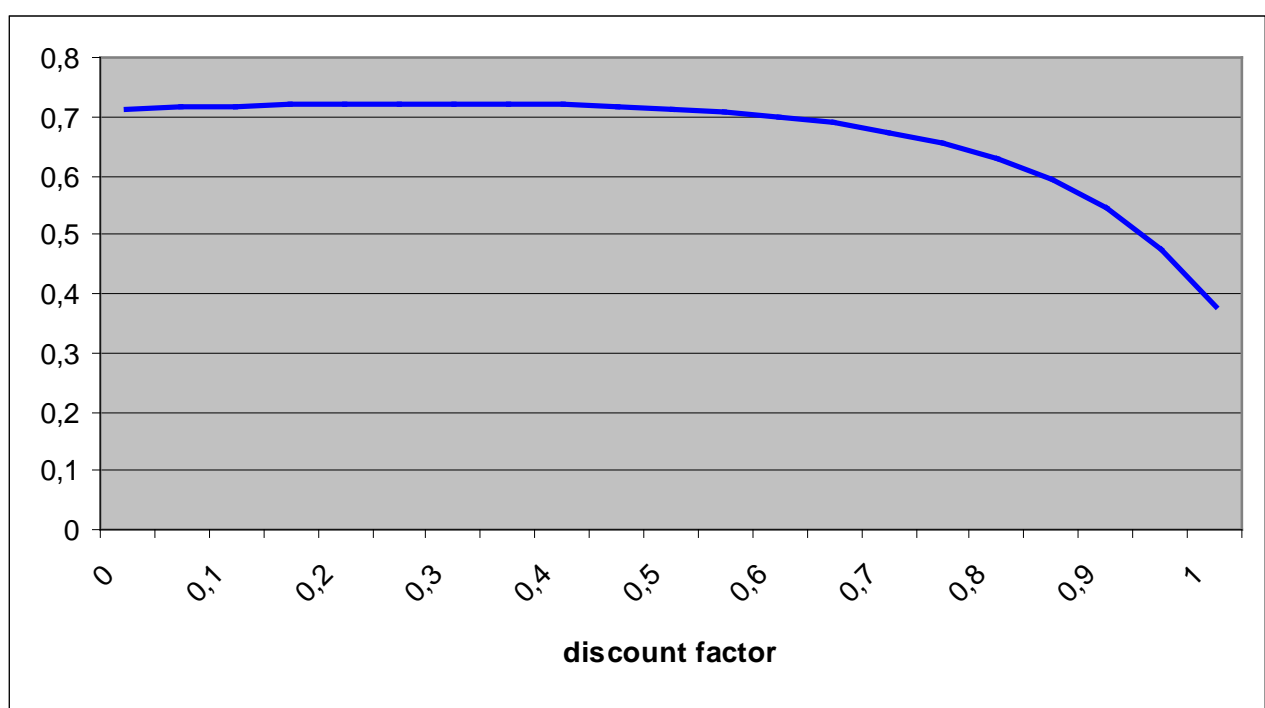




\section{Acknowledgement}

I would like to thank Prof. Claire W. Armstrong and Prof. Derek J. Clark, University of Tromso, for very useful comments and suggestions during the work with this paper. Further, I would like to thank Prof. Geir B. Asheim, University of Oslo, for updated and useful suggestions regarding literature on sequential bargaining models. Also thanks to Prof. Joel Sobel, University of California, San Diego, who verified that the perfect no-commitment sequential bargaining equilibrium which he and Prof. Ichiro Takahashi investigated (1983) could be extended in the way suggested in this paper (but of course not that it was correctly done). Finally, I would like to thank Associate Prof. Martha Saboya, Universidad Autonoma Madrid, for mathematical assistance. Thanks also to very thorough and useful comments from three reviewers. All errors in the paper are of course the responsibility of the author. 


\section{References}

Aanesen M (2006a) To Russia with love? Four essays on public intervention under asymmetric intervention: The Petsjenganikel case on the Kola peninsula. Dissertation. Norut report no 08/2006

Aanesen M (2006b) Public intervention in a 'take-it-or-leave-it' transaction situation under varying interests of the intervening body, Environment and Development Economics 11: 393-409

Ausubel LM, Deneckere RJ (1989) A Direct Mechanism Characterisation of Sequential Bargaining with One-Sided Incomplete Information. Journal of Economic Theory 48: 18-46

Ausubel LM, Deneckere RJ (1993) Efficient Sequential Bargaining. The Review of Economic Studies 60: 435-461

Chambers PE, Jensen RA (2002) Transboundary Air Pollution, Environmental Aid, and Political Uncertainty. Journal of Environmental Economics and Management 43: 93-112

Caparros A, Pereau JC, Tazdait T (2004) North-South Climate Change Negotiations: A Sequential Game with Asymmetric Information. Public Choice 121: $455-480$

Fudenberg D, Levine D, Tirole J (1985) Infinite-horizon models of bargaining with one-sided incomplete information. In A. Roth (ed) Game-theoretic models of bargaining 73-98. Cambridge University Press.

Fudenberg D, Tirole J (1983) Sequential Bargaining with Incomplete Information. Review of Economic Studies 221-247

Fudenberg, D., Tirole, J. (1993). Game Theory $3^{\text {rd }}$ ed. The MIT Press Gul F, Sonnenschein H, Wilson R (1986) Foundations of Dynamic Monopoly and the Coase Conjecture. Journal of Economic Theory 39: 155-190 
Herander, MG (1995) A welfare theoretic argument for regional subsidisation of industry in the presence of inferior technology, Open Ec Review 6, 255-263 Jackson T, Begg K, Parkinson S (2001) Flexibility in Climate Policy. Making the Kyoto mechanisms work. Earthscan Publications, London

Kola Science Centre, Ekono Environmental Technology, 3E Economics (1992) Evaluation of key environmental impacts of Pechenga-Nikel modernisation Project. Volume 1 Final report Laplante, B. (1990) Producer surplus and subsidization of pollution control device: a non-monotonic relationship, Journal of industrial Economics 39: 15-23 Norwegian Ministry of the Environment (2007) Answer to question 615 about Norwegian support to the modernisation of the nickel plant on Kola. Letter to Stortinget (the National Parliament) 26. February 2007

Ready, RC, Malzubris, J, Senkane, S (2002) The relationship between environmental values and income in a transition economy: surface water quality in Latvia, Environment and Development Economics 7, 147-156

Sobel J, Takahashi I (1983) A Multi-Stage Model of Bargaining. Review of Economic Studies 411-426

Spencer BJ, Brander JA (1983) International R\&D Rivalry and Industrial Strategy. Review of Economic Studies 50: 707-722

Smith-Sivertsen, A (2000) Air pollution and health in the Norwegian-Russian border area. A cross-sectional population based study of the impact of nickel and sulphur dioxide, Institute of community medicine, University of Tromso www.amap.no www.eea.europa.eu 